April 1999 • NREL/CP-520-25857

\title{
The Morphology and Microstructure of Thin-Film GaAs on Mo Substrates
}

K.M. Jones, M.M. Al-Jassim, and F.S. Hasoon National Renewable Energy Laboratory

R. Venkatasubramanian Research Triangle Institute

Presented at the National Center for Photovoltaics Program Review Meeting Denver, Colorado September 8-11, 1998

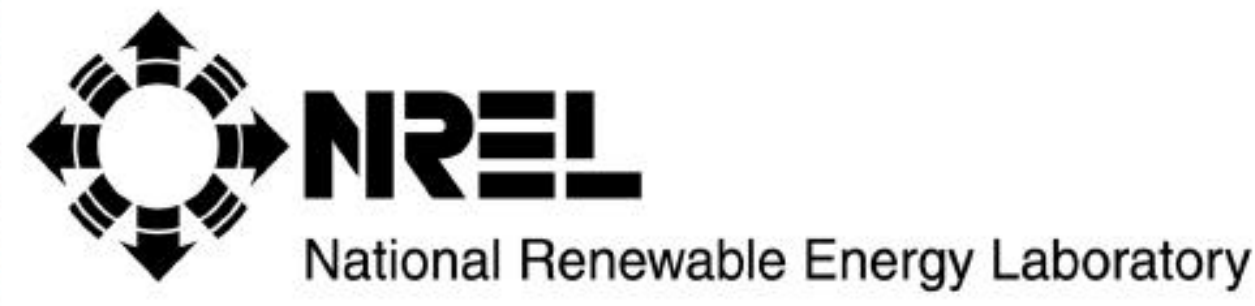

1617 Cole Boulevard Golden, Colorado 80401-3393

NREL is a U.S. Department of Energy Laboratory Operated by Midwest Research Institute $\cdot$ Battelle $\cdot$ Bechtel 


\section{NOTICE}

This report was prepared as an account of work sponsored by an agency of the United States government. Neither the United States government nor any agency thereof, nor any of their employees, makes any warranty, express or implied, or assumes any legal liability or responsibility for the accuracy, completeness, or usefulness of any information, apparatus, product, or process disclosed, or represents that its use would not infringe privately owned rights. Reference herein to any specific commercial product, process, or service by trade name, trademark, manufacturer, or otherwise does not necessarily constitute or imply its endorsement, recommendation, or favoring by the United States government or any agency thereof. The views and opinions of authors expressed herein do not necessarily state or reflect those of the United States government or any agency thereof.

Available to DOE and DOE contractors from:

Office of Scientific and Technical Information (OSTI)

P.O. Box 62

Oak Ridge, TN 37831

Prices available by calling 423-576-8401

Available to the public from:

National Technical Information Service (NTIS)

U.S. Department of Commerce

5285 Port Royal Road

Springfield, VA 22161

$703-605-6000$ or $800-553-6847$

or

DOE Information Bridge

http://www.doe.gov/bridge/home.html

Printed on paper containing at least $50 \%$ wastepaper, including $20 \%$ postconsumer waste 


\title{
The Morphology and Microstructure of Thin-Film GaAs on Mo Substrates
}

\author{
K.M. Jones, M.M. Al-Jassim, F.S. Hasoon, and R. Venkatasubramanian* \\ National Renewable Energy Laboratory (NREL), 1617 Cole Blvd., Golden, Colorado 80401 \\ * Research Triangle Institute, Research Triangle Park, NC 27709
}

\begin{abstract}
The growth of GaAs thin films on Molybdenum foils was investigated in an attempt to find a low-cost substrate for GaAs. The films were grown by metalorganic chemical vapor deposition (MOCVD). The film thickness was in the $2-4 \mu \mathrm{m}$ range, while the deposition temperature was in the $650^{\circ}-825^{\circ} \mathrm{C}$ range. Scanning electron microscopy (SEM) and transmission electron microscopy (TEM) were used to investigate the film morphology and microstructure, respectively. The film morphology in general, and the grain size in particular, were found to be strongly dependent on the growth temperature. However, the defect structure observed in these films was relatively insensitive to the growth conditions.
\end{abstract}

\section{INTRODUCTION}

Single-junction GaAs and dual-junction GaAs/GaInP solar cells epitaxially grown on singlecrystal GaAs substrates have achieved record efficiencies of $25.7 \%$ [1] and 30\% [2], respectively. GaAs/GaInP tandem cells are currently in production for space applications, and several satellites are already powered by this technology. However, significant cost reduction is required in order to make such cells viable candidates for terrestrial applications. Many studies have been carried out on the cost of producing these cells for flat-panel terrestrial applications. The cost of the GaAs substrate has long been considered a major contributor to the overall cost.

Various studies have explored the use of lower-cost substrates for GaAs. In the mid-to-late 1980s considerable efforts were directed at the heteroepitaxial growth of III-Vs (GaAs, GaP, and $\mathrm{InP}$ ) on Si substrates for solar cell applications. The primary incentive for this work was the cost reduction of expensive substrate materials. This is particularly important when considering large-scale production of terrestrial photovoltaic modules. In the United States, these efforts produced cell efficiencies up to $17 \%$. Continued development of this solar cell structure is currently being pursued in Japan [3]. Similar cost-effective structures are being investigated at NREL, including the growth of polycrystalline GaAs films on glass substrates. Polycrystalline films, however, tend to contain a high density of grain boundaries and intragrain defects, which are regions of enhanced carrier recombination. Such recombination is known to have a deleterious effect on cell performance. In order to reduce the detrimental effects of grain boundaries, the growth of large-grain (hence low-grain-boundary density) GaAs is being investigated. 
In this study, we report SEM and TEM investigations of the nucleation, growth and microstructural properties of GaAs films deposited on Mo foils. The main objective of the work is to investigate Mo as a possible alternative substrate. The PV community has extensive experience with Mo, resulting from its wide use as a substrate for CIS solar cells.

The GaAs films were deposited by MOCVD. The growth temperature was in the $650^{\circ}-$ $825^{\circ} \mathrm{C}$ range, while the film thickness was in the $2-4 \mu \mathrm{m}$ range. Additionally, the effects of dopants were investigated using $\mathrm{Si}, \mathrm{Se}$, and $\mathrm{Zn}$.

\section{RESULTS}

Figure 1 shows SEM micrographs of the surface of films deposited at $650^{\circ}, 725^{\circ}$, and $775^{\circ} \mathrm{C}$. Clearly, these films are compact, exhibiting very rough surfaces, with an
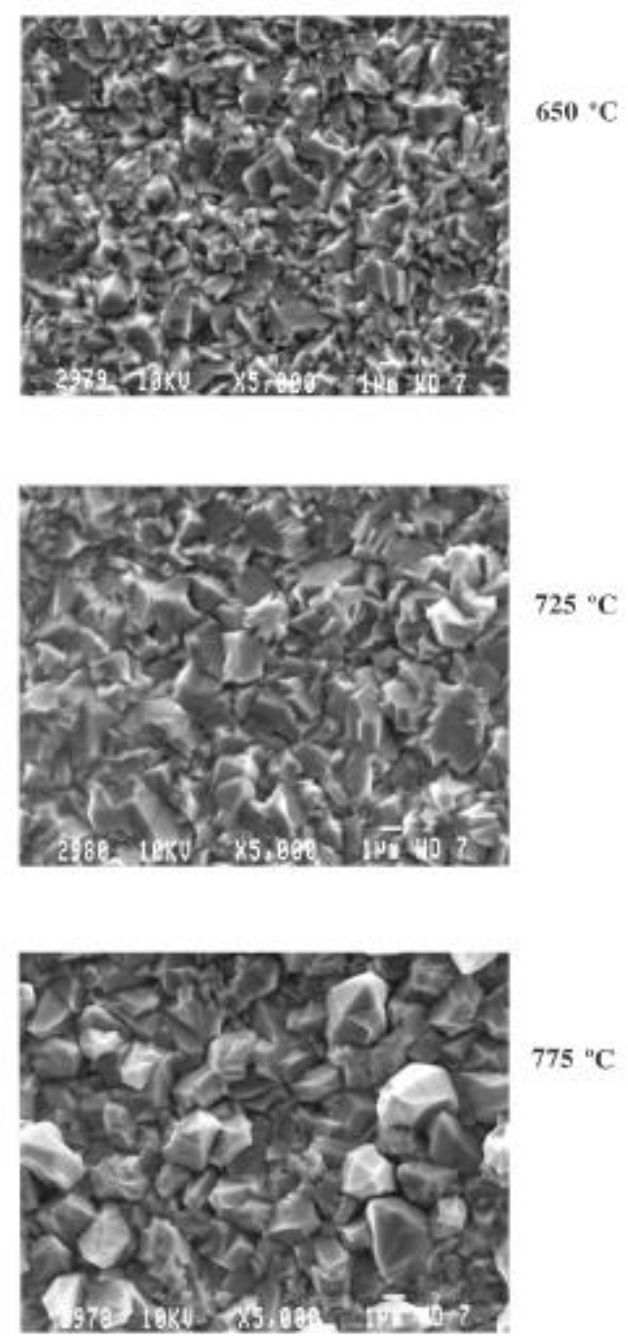

FIGURE 1. SEM micrographs of GaAs films deposited at three different temperatures, keeping all other conditions constant. 
increasing roughness as the deposition temperature increases. Further, many of the grains are faceted. Again, the degree of faceting seems to increase markedly with the deposition temperature. At $775^{\circ}$ and $825^{\circ} \mathrm{C}$, the grains are highly faceted and the surface roughness is on the order of $1 \mu \mathrm{m}$. The growth temperature was also found to have a profound effect on the grain size, with a significant increase at higher temperatures. Figure 2 shows the resulting dependence of grain size on growth temperature. The grain size exhibits a very well defined behavior as a function of temperature, rising by a factor of 1.5 as the temperature is raised from $650^{\circ}$ to $775^{\circ} \mathrm{C}$. We believe that this increase is due to increasing mobility of adsorbed atoms on the growth surface with the increasing temperature. At $825^{\circ} \mathrm{C}$, a slight decrease in grain size was observed in comparison with $775^{\circ} \mathrm{C}$. This behavior is not clear at present, but is likely caused by a change in growth mode to a more columnar growth. In addition to the effect of the growth temperature, we studied the morphology of these films as a function of dopant, keeping all the growth conditions the same. No detectable differences in the surface morphology were observed in films doped with $\mathrm{Si}$, Se, and $\mathrm{Zn}$. TEM cross-sectional examination clearly revealed the morphology and the microstructure of the films along the entire film thickness. At low temperature growth (Fig. 3), the film surface is fairly smooth; however, the film's surface roughness increased dramatically with increasing growth temperature. These results corroborate what we observed by SEM. Cross-sectional examinations also revealed that the growth mode is very temperature dependent. Films deposited at relatively low temperatures (Fig. 3) exhibited small grain size in the vicinity of the. Mo/GaAs interface, and the grain size increased with increasing film thickness.

\section{Grain size vs. Growth temperature}

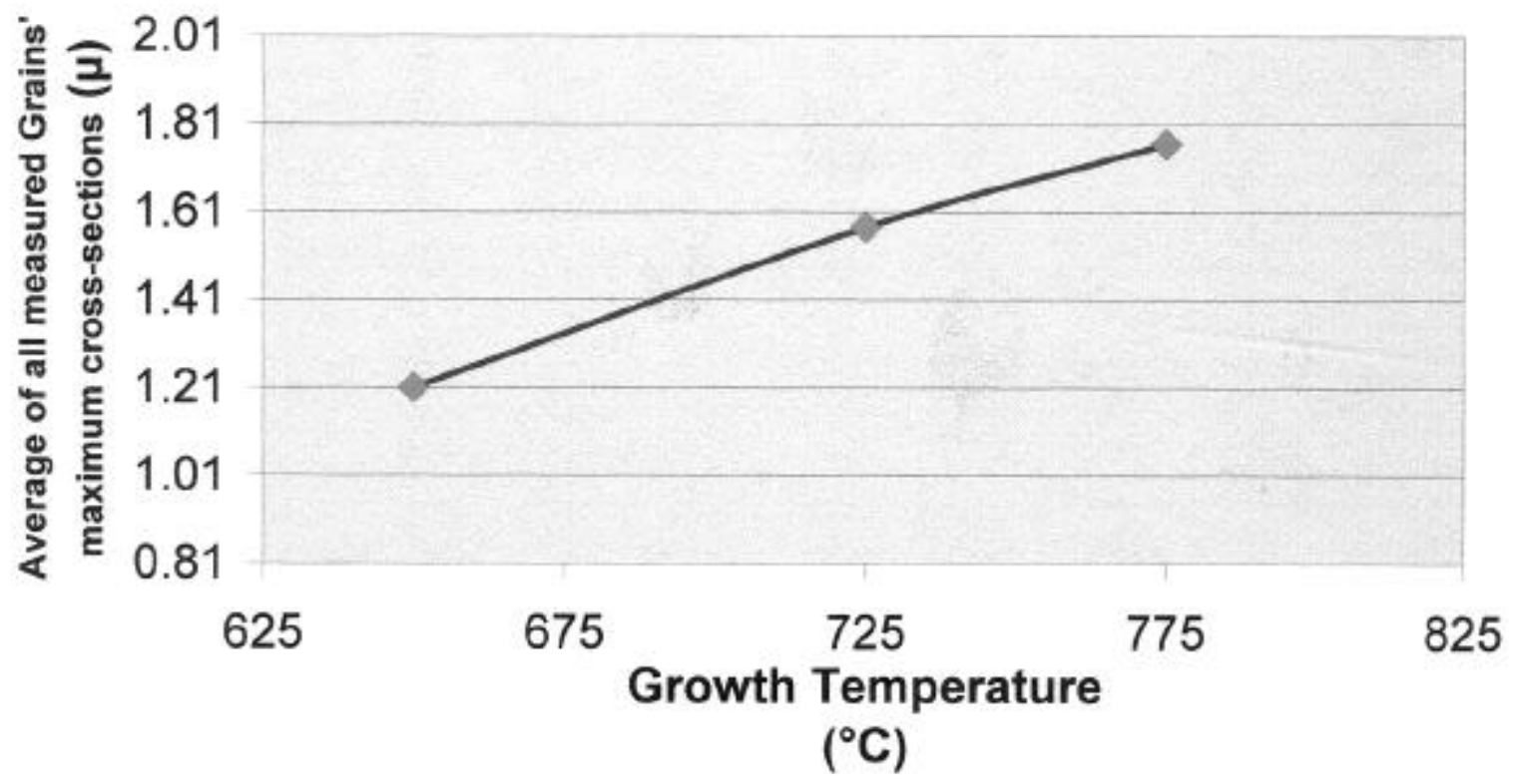

FIGURE 2. Plot of grain size vs. growth temperature 


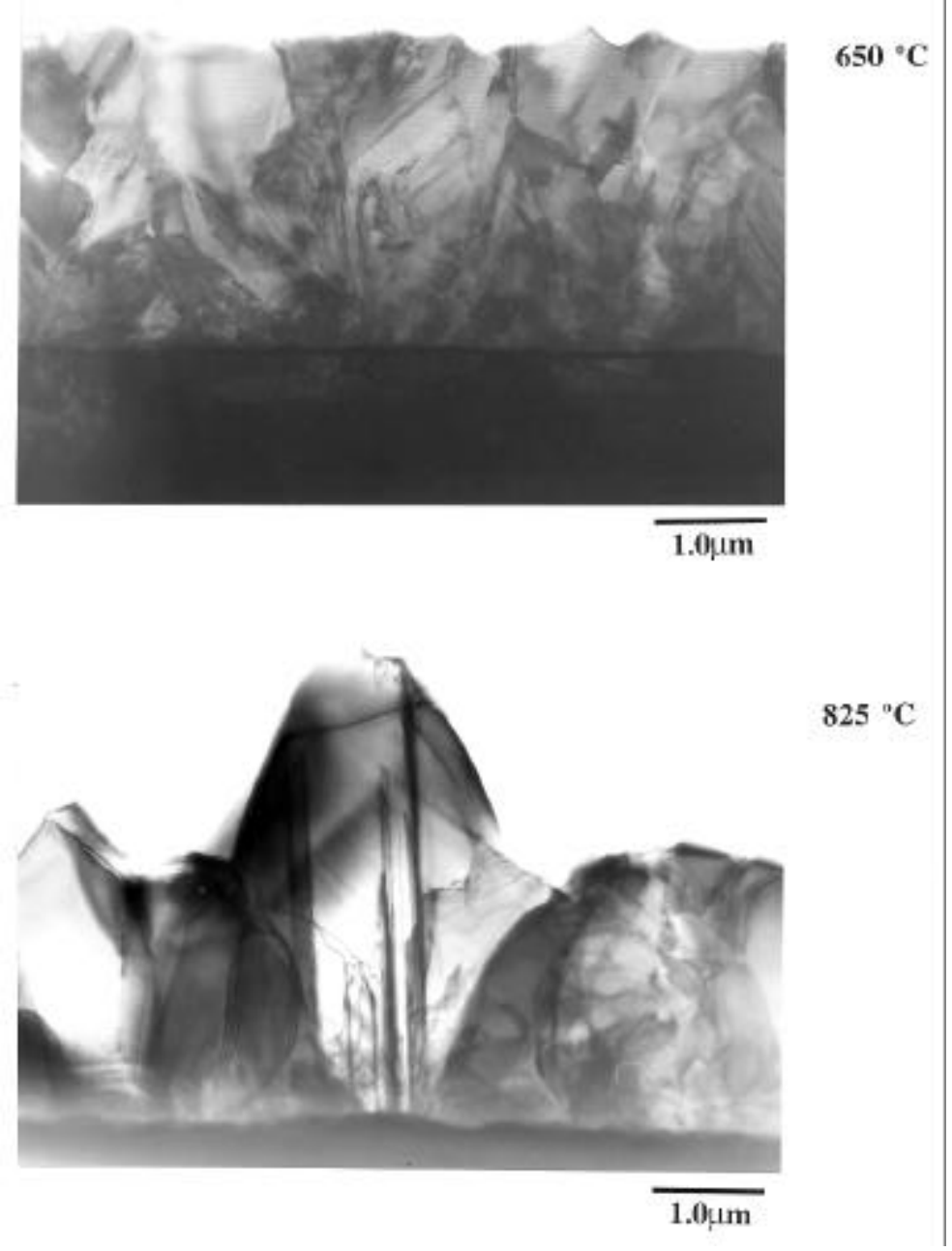

FIGURE 3. TEM cross-sectional micrographs of GaAs films deposited at $650^{\circ} \mathrm{C}$ and $825^{\circ} \mathrm{C}$, showing the effect of deposition temperature on the morphology and growth mode.

Films deposited at high temperatures, on the other hand, exhibited more columnar growth morphology.

TEM cross-sectional examination also revealed the nature, density, and three-dimensional distribution of structural defects. On the whole, these films are very heavily faulted. High densities of threading dislocations and stacking faults were observed in all films regardless of the deposition conditions. The defect density, however, decreased markedly with film thickness.

Detailed plan-view TEM examination was carried out on these films. The results were in agreement with what we gleaned from our cross-sectional study. Particular emphasis was placed on studying the defect structure in these films as a function of growth temperature. 
Figure 4 shows TEM plan view micrographs of films grown at $650^{\circ}$ and $825^{\circ} \mathrm{C}$. Clearly these films are heavily defective with defect densities well above $10^{8} \mathrm{~cm}^{2}$.
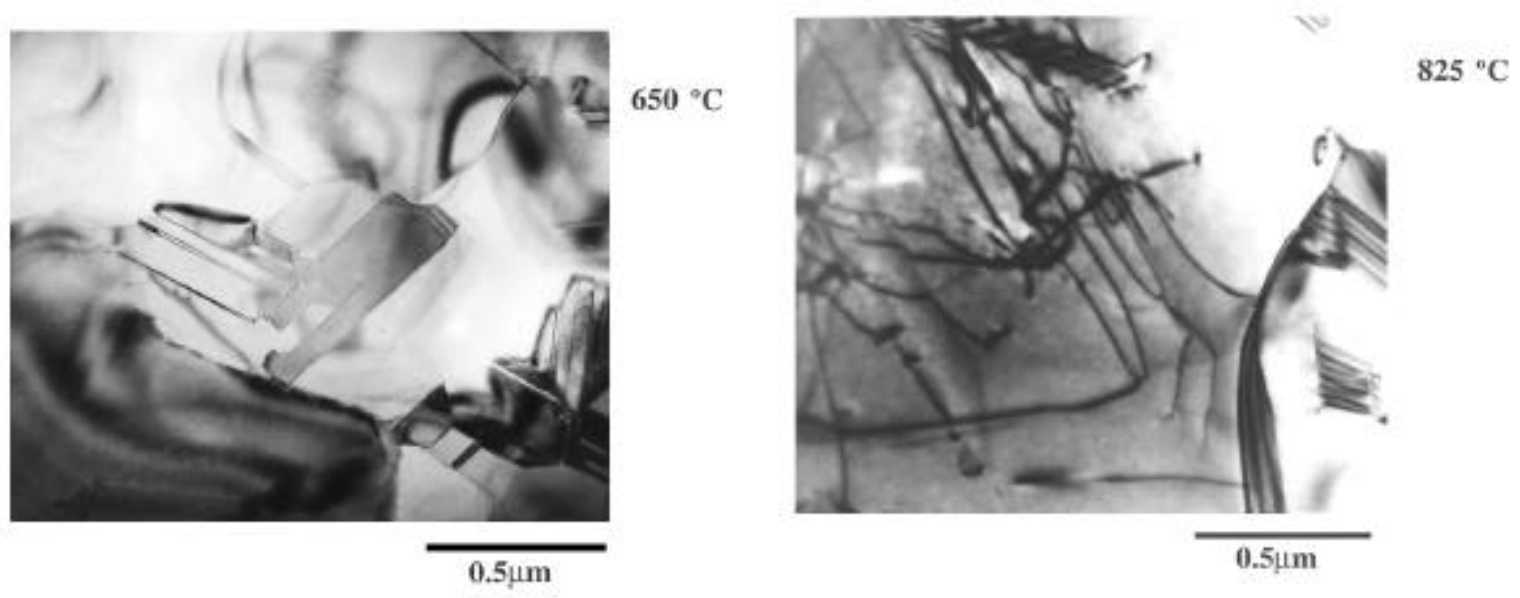

FIGURE 4. TEM plan-view micrographs of GaAs films deposited at $650^{\circ} \mathrm{C}$ and $825^{\circ} \mathrm{C}$ showing the nature, density, and distribution of structural defects.

Furthermore, the defect density and type varied from one grain to another. However, on the whole, higher density of planar defects (such as stacking faults) was observed at lower growth temperatures, and higher density of threading dislocations was observed at higher growth temperatures. The latter is believed to be caused by the increased ductility of the material at higher temperatures, and the corresponding increase in dislocation velocity and the probability of dislocation multiplication.

The most significant finding in this study is the unambiguous presence of high densities of intragrain extended defects and grain boundary defects. This clearly explains the poor minority carrier properties in these films. In order to make these films viable candidates for solar cell material, means of reducing the defect density and/or passivating these defects must be devised.

\section{SUMMARY}

The morphology and microstructure of GaAs thin films deposited on low-cost Mo foils were investigated. The films were revealed to be polycrystalline, with varying grain size. The grain size increased monotonically with deposition temperature, but was not affected by the type of dopant used. These films are heavily faulted with high densities of planar and linear crystallographic defects. The overall defect density was not significantly affected by the deposition conditions. The presence of such high densities of intragrain and grain-boundary defects explains the poor minority-carrier properties in these films. In order to make these films viable candidates for solar cell applications, means of reducing the defect density and/or passivating the electrical activity of the defects must be devised. 


\section{ACKNOWLEDGMENT}

This work is supported by the U.S. Department of Energy under contract number DE-AC36-83CH10093

\section{REFERENCES}

1. S.R. Kurtz, J.M. Olson, and A. Kibbler, Proc. of 21st IEEE PVSC (IEEE Press, NY 1990) p. 138.

2. D.J. Friedman, S.R. Kurtz, K.A. Bertness, A.E. Kibbler, C. Kramer, and J.M. Olson, Prog in Photovolt., 3, 1995, p. 47.

3. Soga et al., JAP 79, 9375, (1996).

4. R. Venkatasubramanian, B.C. O'Quinn, J.S. Hills, P.R. Sharps, M.L. Timmons, and J.A. Hutchby, Proc. 25th IEEE PVSC (1996) p. 31.

5. S.S. Chu, T.L. Chu, and H.T. Yang, Appl. Phys. Lett. 32, 1978, p. 557. 